\title{
Efeito do estádio de maturação, tipo de inóculo e local de inoculação na severidade da podridão peduncular em manga
}

\author{
Thiago Alves S. Oliveira, Sônia Maria A. Oliveira, Sami J. Michereff, Marcos P.S. Câmara, Valéria S.O. \\ Costa \& Severina R.O. Lins
}

Universidade Federal Rural de Pernambuco, Departamento da Agronomia, Área de Fitossanidade, 52171-900, Recife, PE, Brasil

Autor para correspondência: Sônia M.A. Oliveira, e-mail: s.oliveira@ufrpe.br

\begin{abstract}
RESUMO
A mangicultura é uma das principais atividades do agronegócio frutícola do Brasil, apresentando desempenho crescente nos últimos anos. As podridões pós-colheita são responsáveis por grande parte das perdas de frutas armazenadas, destacando-se sobre mangas os fungos Lasiodiplodia theobromae e Fusicoccum parvum. Este trabalho teve como objetivo comparar isolados das espécies L. theobromae e F. parvum, quanto à agressividade, tipo de inóculo, local de inoculação e estádio de amadurecimento na cv. Tommy Atkins. O teste de agressividade foi realizado com cinco isolados de L. theobromae e 10 de F. parvum, através da medição do diâmetro da lesão após sete dias da inoculação dos fitopatógenos. Os isolados L2 e L5 de L. theobromae e os isolados F6 e F10 de F. parvum foram os mais agressivos. Os mesmos foram testados em relação ao estádio de maturação $(2 ; 2,5 ; 3 ; 4$ e 5), tipo de inóculo (disco de meio BDA contendo estruturas dos fitopatógenos e suspensão de conídios $-10^{5}$ conídios $/ \mathrm{mL}$ ) e local de inoculação (região peduncular e equatorial) na manga. De modo geral, à medida que avançava o amadurecimento, aumentava a severidade da doença para os isolados dos dois fitopatógenos, independente do local de inoculação e do tipo de inoculo. Nos estádios iniciais de maturação, menores lesões foram observadas quando os fitopatógenos foram inoculados com suspensão de conídios. Quanto ao local de inoculação, não se observou influência pronunciada deste para os isolados dos fitopatógenos estudados.
\end{abstract}

Palavras-chave: Mangifera indica, Lasiodiplodia theobromae, Fusicoccum parvum, pós-colheita.

ABSTRACT

Effect of maturation stage, inoculum type, and inoculation region on stalk rot severity in mango

The mango crop is one of the principal activities of Brazilian agribusiness, and it has grown steadily over recent years. Postharvest rots are responsible for great losses in fruit storage, with prominence to steam-end rot, caused by Lasiodiplodia theobromae and Fusicoccum parvum. The objective of this work was to compare isolates of the species $L$. theobromae and F. parvum on the aggressivity, inoculum type, inoculation place and state of ripeness in cv. Tommy Atkins. The aggressivity test was carried out with five isolates of $L$. theobromae and 10 isolates of $F$. parvum. Isolates L2 and L5 of $L$. theobromae and isolates $\mathrm{F} 6$ and F10 belonging to the species $F$. parvum were considered the most aggressive. These isolates were tested in relation to the state of ripeness $(2 ; 2,5 ; 3 ; 4$ and 5 ), inoculum type (disc of PDA containing structures of the plant pathogens and conidia suspension $-10^{5}$ conidium $/ \mathrm{mL}$ ) and inoculation place (peduncle region and equatorial area) on the mango. In general, the more mature the fruit, the greater the severity of the disease for isolates of the two plant pathogens, independent of the place of inoculation and the type of inoculum. In the earliest states of ripeness the smallest lesions were observed when inoculated with conidium suspension. As for the inoculation place, no marked influence was observed for the isolates of the plant pathogens studied Keywords: Mangifera indica, Lasiodiplodia theobromae, Fusicoccum parvum, postharvest.

\section{INTRODUÇÃO}

A manga (Mangifera indica L.) é uma das mais importantes frutas tropicais da história da humanidade (Silva, 1996). Seus principais produtores são Índia, China, Tailândia, México, Indonésia e Brasil (FAO, 2007). O destaque do Brasil na produção mundial está diretamente envolvido aos projetos de irrigação dispostos no Vale do São Francisco, voltados para a produção de manga destinada ao mercado externo. Entre os estados brasileiros vale destacar Bahia e Pernambuco na exportação mundial dessa fruta (Okasaki, 2007). Dentre as frutas atualmente comercializadas, a manga é a oitava colocada em volume de comercialização no mundo, em função do seu amplo consumo nos países asiáticos e da América Latina (Agrianual, 2006). De acordo com Almeida et al. (2005), a mangicultura é uma das principais atividades do agronegócio frutícola do Brasil, apresentando desempenho crescente nos últimos anos. A demanda mundial por frutas e hortaliças vem crescendo expressivamente, entretanto a magnitude das perdas pós-colheita de produtos hortícolas preocupa, sendo mais expressivas nas regiões tropicais, devido às condições ambientais favoráveis, que permite o desenvolvimento de pragas e doenças (Oliveira et al., 2006). 
A evolução da patogenicidade de microrganismos, estimulada pelas pressões ambientais, tem revelado uma gama de patógenos primários, antes tidos como secundários. Isso ocorreu com Lasiodiplodia theobromae (Pat.) Griffon e Maubl., principalmente nas regiões semi-áridas onde são constatadas altas severidades de doença, devido às condições climáticas mais ou menos uniformes durante todo o ano e favoráveis ao seu desenvolvimento (Tavares et al., 1991). Levantou-se a hipótese que $L$. theobromae tenha evoluído em patogenicidade em conseqüência das pressões ambientais, especialmente nessa região (Tavares, 2002). Trabalho recente revelou um aumento no número de hospedeiros e na severidade do ataque deste fitopatógeno (Freire et al., 2004). No Brasil, em levantamento realizado por Tavares (1995) em fruteiras de áreas irrigadas do semi-árido nordestino, observou-se que este patógeno é responsável por grandes problemas fitossanitários no Vale do São Francisco. Na pós-colheita, L. theobromae tem registro em todas as regiões produtoras de manga do mundo, causando problema quando o pedúnculo da fruta é infectado, devido à podridão peduncular e infecções nas partes laterais da polpa, que a desqualifica para o mercado (Angel et al., 2006).

Estudos têm relatado espécies de Fusicoccum infectando mangas na Califórnia(Ramosetal., 1991)e abacate na Nova Zelândia (Hartill, 1991). Isolados de Dothiorella dominicana Petr. \& Cif. foram encontrados infectando mangas na Australia (Johnson, 1992), sendo identificados como a espécie Fusicoccum parvum Pennycook \& Samuels (Pennycook \& Samuels, 1985; Slippers et al., 2004; 2005). Johnson (1992) mostra claramente que $F$. parvum (reportada como D. dominicana) é um dos fitopatógenos mais comuns infectando mangueira, causando morte dos ponteiros, queima de botão na mangueira e podridão peduncular em frutas.

No hemisfério norte, fungos do gênero Fusicoccum tem causado sérios prejuízos em pomares de ameixeira (Prunus domestica L.), localizados em regiões úmidas, onde uma infecção severa pode acarretar a morte da planta, sendo observado em épocas de muita chuva, em pomares mal cuidados, na maioria das cultivares plantadas comercialmente. No sul do Brasil, tem sido encontrada com freqüência em pomares de pessegueiros (Prunus persicae L.) (Andrade \& Docroquet, 2002). Diante do exposto e pela importância que essa fruta representa na cadeia produtiva, esse trabalho teve como objetivo avaliar a agressividade de isolados de L. theobromae e de F. parvum e o efeito do tipo de inóculo, local de inoculação e estádio de maturação na severidade da podridão peduncular na cultivar de manga Tommy Atkins em pós-colheita.

\section{MATERIAL E MÉTODOS}

\section{Obtenção dos isolados}

Os isolados de L. theobromae (L1, L2, L3, L4, L5) e F. parvum (F1, F2, F3, F4, F5, F6, F7, F8, F9, F10) foram cedidos pela Micoteca do Laboratório de Micologia, Área de Fitossanidade, Departamento de Agronomia da Universidade
Federal Rural de Pernambuco (UFRPE). Os fungos foram isolados a partir de mangas cv. Tommy Atkins com sintomas característicos de podridão peduncular. Os fitopatógenos foram obtidos nas localidades assim discriminadas: Afonso Bezerra/ RN (L5), Petrolina/PE (L1, L2, L3, L4, F1, F2, F5, F6, F7, F8 e F9), Casa Nova/BA (F3 e F4) e Ipanguaçu/ RN (F10). Todos os isolados foram repicados para placas de Petri e tubos de ensaio contendo meio Batata-Dextrose-Ágar (BDA) e preservados pelo método de Castellani (Menezes \& Assis, 2004).

\section{Avaliação da agressividade}

O experimento foi realizado no Laboratório de Patologia Pós-colheita, Área de Fitossanidade, Departamento de Agronomia da UFRPE, onde os 15 (cinco de L. theobromae e 10 de $F$. parvum) isolados ficaram incubados em placas de Petri com meio BDA durante 25 dias a temperatura de $25 \pm 2^{\circ} \mathrm{C}$ e alternância luminosa (12 horas claro/12 horas escuro), tempo necessário para a formação de estruturas reprodutivas.

$\mathrm{Na}$ avaliação da agressividade foram utilizadas mangas no estádio de maturação entre 2,5 e 3 (Assis, 2004). As mangas, após lavagem com sabão e água corrente e secas em temperatura ambiente, receberam ferimentos provocados com auxílio de um furador com oito estiletes de $2 \mathrm{~mm}$ de profundidade na região equatorial da fruta, sendo depositado um disco de meio BDA com $5 \mathrm{~mm}$ de diâmetro contendo estruturas dos fitopatógenos. A testemunha foi inoculada com disco do meio BDA na região equatorial. Adotou-se o delineamento experimental inteiramente casualizado, com cinco repetições por isolado, sendo cada parcela representada por uma fruta e perfazendo um total de 75 frutas. As frutas inoculadas foram mantidas em câmara úmida por $48 \mathrm{~h}$, sendo essa composta de um saco plástico umedecido com água destilada. A agressividade dos isolados foi mensurada após cinco dias, depois de retirada a câmara úmida, determinandose a área lesionada externa através da medição do diâmetro da lesão em dois sentidos diametralmente opostos com auxílio de um paquímetro.

Influência do tipo de inóculo, local de inoculação e estádio
de maturação na severidade da podridão peduncular em
manga
Diante dos resultados obtidos no experimento anterior, foram eleitos dois isolados de L. theobromae (L2 e L5) e dois de F. parvum (F6 e F10). As mangas da cv. Tommy Atkins foram previamente lavadas com água e sabão e secas ao ar em temperatura ambiente. Os tratamentos consistiram da deposição de um disco de meio BDA contendo estruturas dos fitopatógenos, sobre ferimentos provocados por um furador contendo oito estiletes de $2 \mathrm{~mm}$ de profundidade, na região peduncular e outras na região equatorial. $\mathrm{O}$ mesmo ocorrendo com a suspensão de conídios, as quais foram ajustadas na concentração de $10^{5}$ conídios $/ \mathrm{mL}$, com auxílio de um hemacitômetro, onde cada fruta recebeu $10 \mu \mathrm{L}$ da mesma. As mangas testemunhas foram inoculadas com 
disco de meio BDA e outras com a deposição de $10 \mu \mathrm{L}$ de água destilada esterilizada na região peduncular e na região equatorial. Após a inoculação, as frutas foram acondicionadas em bandejas plásticas, contendo cinco frutas por cada tipo de inóculo e local de inoculação, e submetidas à câmara úmida por $48 \mathrm{~h}$. Os estádios de maturação utilizados foram: estádio 2, estádio 2,5, estádio 3, estádio 4, e estádio 5 (Assis, 2004). A mensuração do diâmetro da lesão provocada pelos fitopatógenos iniciou-se após a retirada da câmara úmida, mediante a utilização de um paquímetro durante cinco dias, a cada $24 \mathrm{~h}$. O delineamento estatístico utilizado foi o inteiramente casualizado em esquema fatorial $2 \times 5$ (dois tipos de inóculo x cinco estádios de maturação). As médias foram comparadas pelo teste de Duncan a 5\% de probabilidade, utilizando o programa Sanest (Zonta \& Machado, 1996). Os experimentos foram conduzidos sob temperatura de 27 $\pm 2^{\circ} \mathrm{C}$, umidade relativa de $65 \pm 5 \%$, temperatura interna da fruta, aferida por meio de um sensor Datalogger $\left(\mathrm{HOBO}^{\circledR}\right)$, de $29 \pm 2{ }^{\circ} \mathrm{C}$.

\section{RESULTADOS E DISCUSSÃO}

\section{Avaliação da agressividade}

Todos os isolados de L. theobromae e de F. parvum estudados mostraram-se patogênicos quando inoculados em manga (Figura 1). Os isolados de L. theobromae foram mais agressivos, com expressão dos sintomas da doença 72 h após a inoculação, enquanto que para os isolados de $F$. parvum os sintomas surgiram $120 \mathrm{~h}$ após a inoculação.

Os sintomas da doença provocados pelos fitopatógenos consistiram na formação de lesões úmidas que adquiriram coloração marrom, resultando na podridão das frutas. Com os isolados de L. theobromae foram observados sintomas como rachadura da epiderme, exsudação de líquido e crescimento micelial na epiderme da fruta, os mesmos descritos por Angel et al. (2006), como característicos de podridão peduncular de $L$. theobromae em manga. Já $F$. parvum não foi observado o aparecimento destes sintomas, o que pode ser uma característica de diferenciação entre esses dois gêneros fúngicos. Com relação à agressividade dos isolados, verificou-se que o isolado L5 foi o mais agressivo ao hospedeiro dentro do mesmo gênero (Figura 1), seguidos dos isolados L2, L3, L1 e L4, sendo o mesmo observado para os isolados F10, F6 e F8 (Figura 1) quando comparado com os isolados F2, F5, F7, F9, F3, F4 de F. parvum. Esses resultados mostram que ocorreram variações quanto à agressividade em diferentes isolados oriundos da mesma cultura. Observouse que os isolados L5 e F10 comportaram-se como os mais agressivos, sendo oriundos da mesma região geográfica (Rio Grande do Norte). Variações na agressividade entre isolados podem ser explicadas por fatores externos, como diferenças edafoclimáticas das regiões de procedência, ou por fatores internos, sendo as diferenças entre espécies ou isolados da mesma espécie resultado de suas características genéticas (Ram,1993; Moraes et al., 1995; Lima, 1996; Perreira et al., 2006).

Influência do tipo de inóculo, local de inoculação e estádio de maturação na severidade da podridão peduncular da manga

Os resultados obtidos com os isolados de $L$. theobromae (L2 e L5) estão dispostos na Figura 2. Observase que, de modo geral, a inoculação com discos contendo estruturas do fitopatógenos resultou em maiores lesões sobre a hospedeira. O estádio de maturação não influenciou no desenvolvimento da doença nos isolados utilizados, exceto
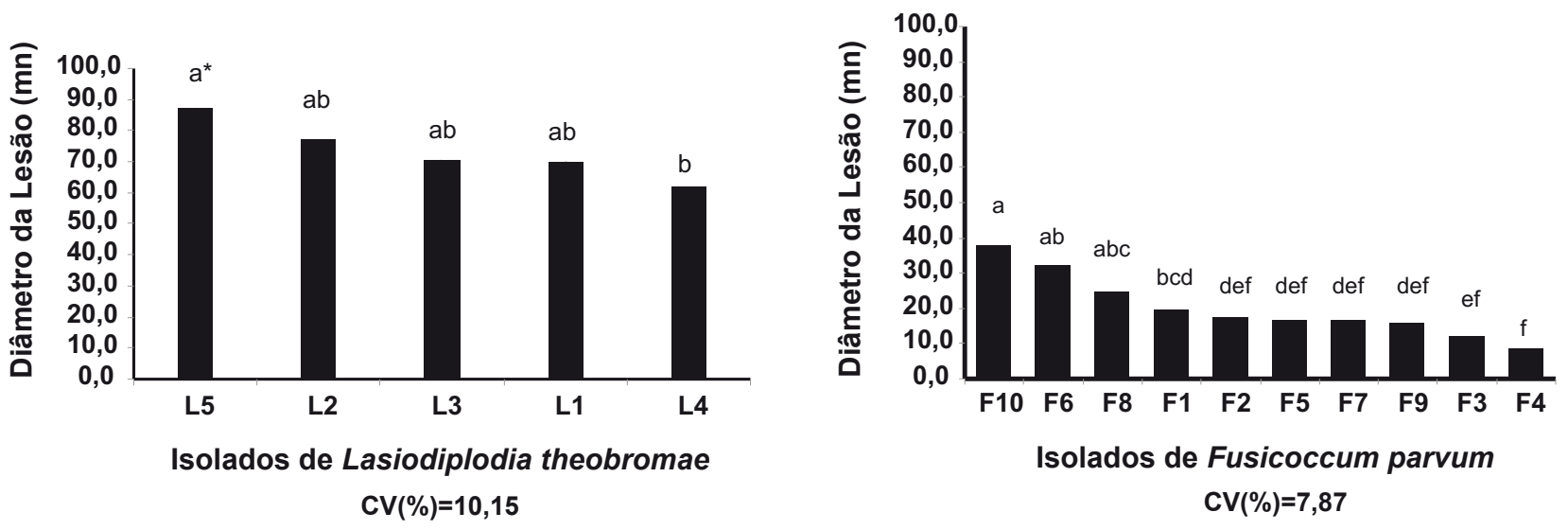

FIG. 1 - Diâmetro da lesão (mm) em manga cv. Tommy Atkins ocasionadas por isolados de Lasiodiplodia theobromae (L1, L2, L3, L4 e L5) e de Fusicoccum parvum (F1, F2, F3, F4, F5, F6, F7, F8, F9 e F10), após sete dias da inoculação.

*Médias seguidas de mesma letra não diferem significativamente entre si pelo teste de Duncan $(\mathrm{P} \leq 0,05)$. Médias de cinco repetições (frutas). 

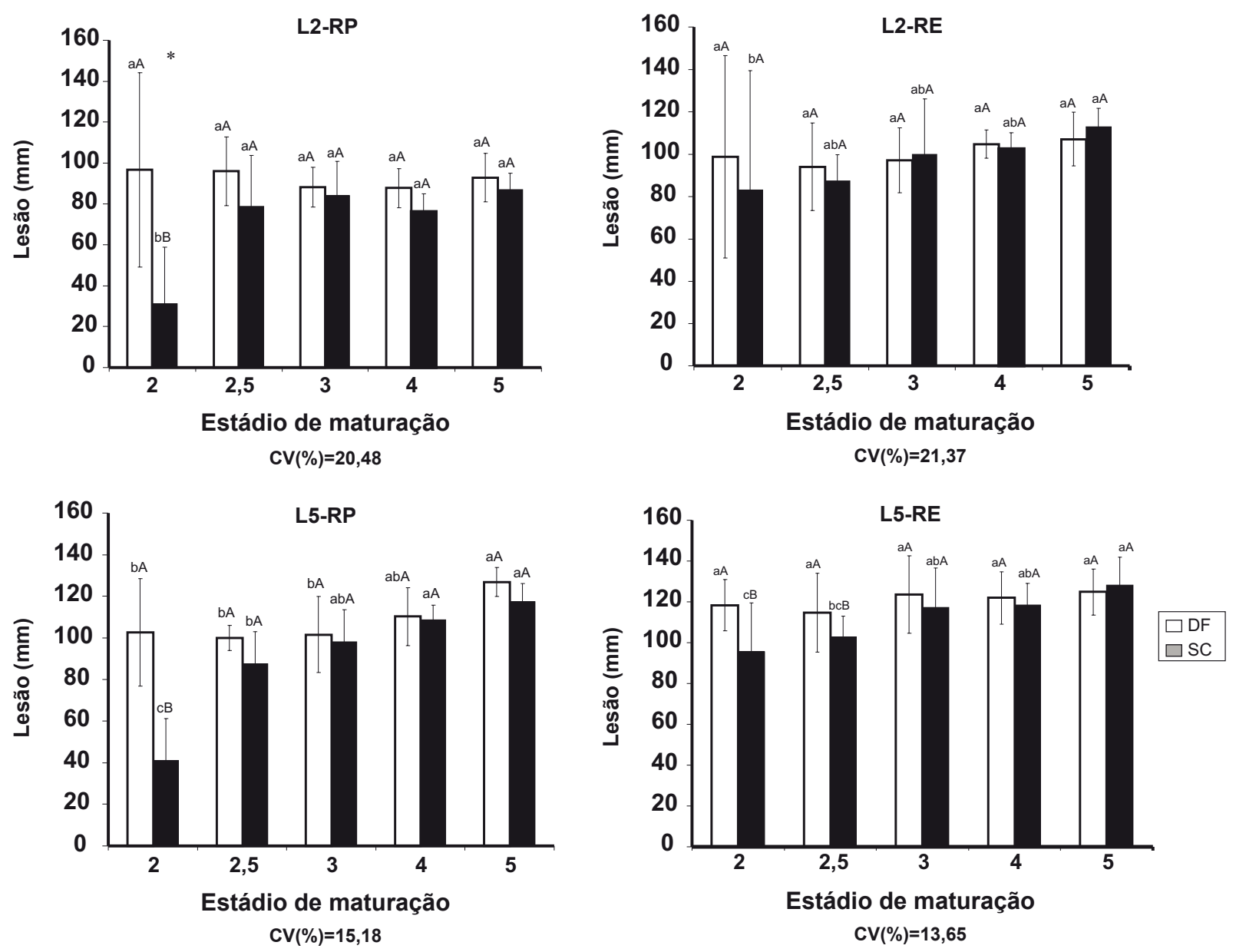

FIG. 2 - Efeito do estádio de maturação e tipo de inóculo (disco com estruturas do fitopatógeno (DF) e suspensão de conídios (SC)) sobre a podridão de Lasiodiplodia theobromae em manga, inoculadas com os isolados L2 e L5 na região peduncular (RP) e na região equatorial (RE).

*Médias seguidas entre si de mesma letra, minúscula dentro da categoria e maiúscula entre as categorias, não diferem significativamente pelo teste Duncan $(\mathrm{P} \leq 0,05)$.

para o L5 que apresentou diferença significativa no estádio 5 de maturação, quando a inoculação do fitopatógeno foi realizada com discos contendo estruturas do fitopatógeno na região peduncular da fruta. Com relação ao local de inoculação (região peduncular e região equatorial), os isolados proporcionaram menores lesões quando inoculados no estádio de maturação 2 com suspensão de conídios, diferindo dos demais estádios, tipo de inóculo e local de inoculação.

Na Figura 3 encontram-se os resultados de F. parvum sobre as mangas. Independente do tipo de inóculo e local de inoculação, as lesões apresentaram valores crescentes à medida que o estádio de maturação avançava. Semelhante ao observado para os isolados de L. theobromae no que se refere ao tipo de inóculo, a inoculação com disco contendo estrutura do fitopatógeno resultou em lesões maiores. No estádio 2 de maturação, ocorreu diferença significativa entre os tipos de inóculo, com a suspensão de conídio proporcionado menor desenvolvimento da lesão, independente do local de inoculação (região peduncular ou equatorial). O método de inoculação utilizando suspensão de conídios justifica-se pela padronização na quantidade de inóculo depositada sobre a superfície do hospedeiro, uma vez que a inoculação com disco de meio de cultura contendo estruturas do fitopatógeno possui uma fonte extra de substrato, o que não ocorre na natureza (Pessoa et al., 2007).

A severidade da doença foi significativamente maior no estádio mais avançado de maturação, concordando com Pessoa et al. (2007), onde observaram que bananas (Musa spp.) em estádio de maturação mais elevado foram altamente suscetíveis à infecção por Colletotrichum musae, enquanto que frutas verdes ou em estádio inicial de maturação apresentam maior resistência a infecção. Chillet et al. (2006) trabalhando com C. musae demonstraram que 

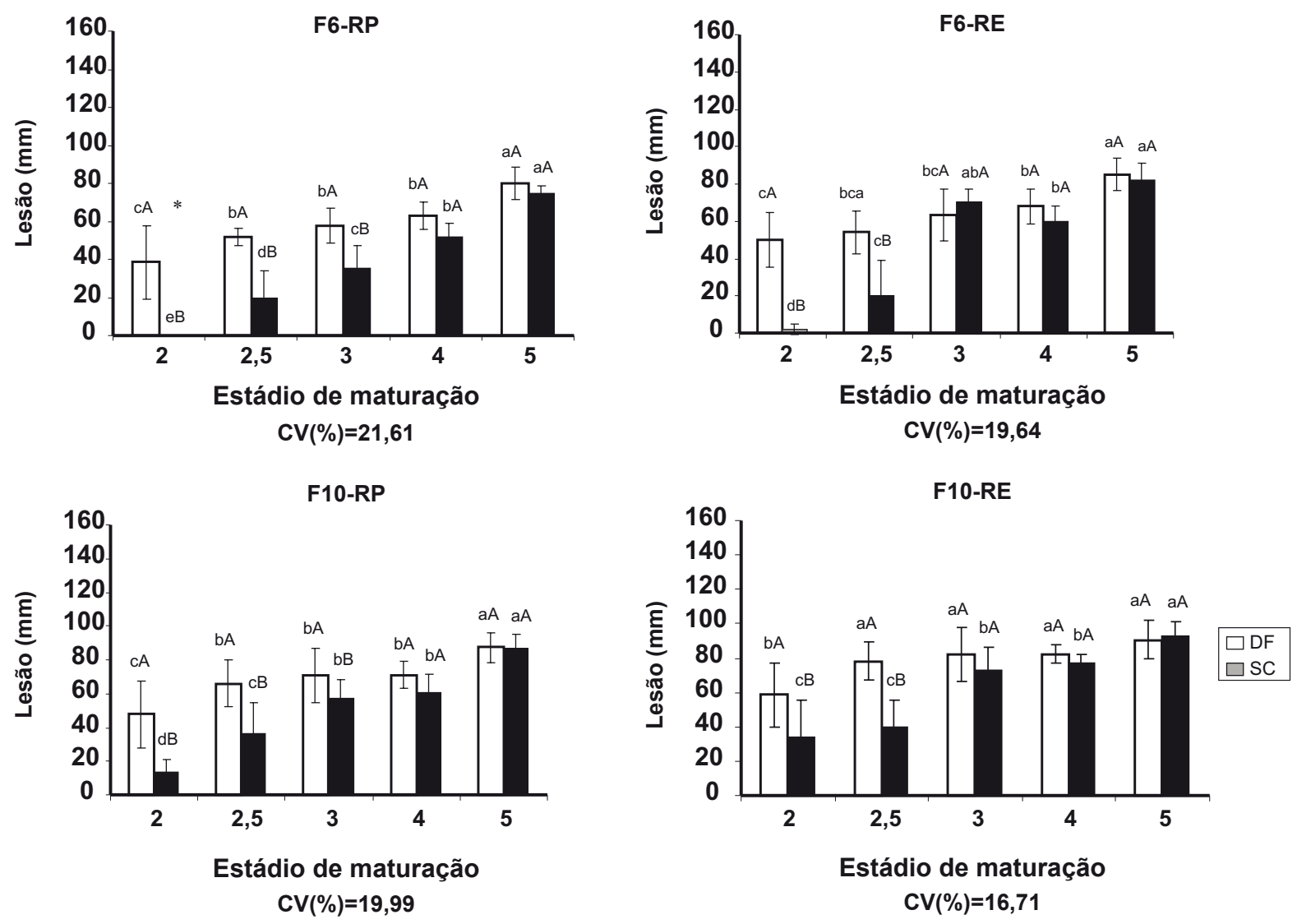

FIG. 3 - Efeito do estádio de maturação e tipo de inóculo (disco com estruturas do fitopatógeno (DF) e suspensão de conídios (SC)) sobre a podridão de Fusicoccum parvum (F6 e F10) em manga, na região peduncular (RP) e na região equatorial (RE).

*Médias seguidas entre si de mesma letra, minúscula dentro da categoria e maiúscula entre as categorias, não diferem significativamente pelo teste Duncan $(\mathrm{P} \leq 0,05)$.

a idade fenológica é um fator chave na suscetibilidade da hospedeira ao fitopatógeno. Geralmente, frutas verdes são mais resistentes a fitopatógenos, devido à presença de fitoalexinas e outros compostos em maior quantidade (Chitarra \& Chitarra, 2005). Este é o primeiro relato a respeito da correlação entre o estádio de maturação, tipo de inóculo e local de inoculação nos patossistemas manga x $L$. theobromae e manga x F. parvum.

\section{REFERÊNCIAS BIBLIOGRÁFICAS}

Agrianual (2007) Anuário da agricultura brasileira. São Paulo SP. FNP Consultoria e Comércio.

Almeida CO, Cardoso CEL, Santana MA (2005) Comercialização. In: Pereira MEC, Fonseca N, Souza FVD (Eds.) Manga: o produtor pergunta, a Embrapa responde. Brasília DF. Embrapa Informação Tecnológica. pp. 177-184.
Andrade ER, Ducroquet JPHJ (2002) Controle das doenças da ameixeira. In: Zambolim L, Vale FXR, Monteiro AJA, Costa H (Eds.) Controle de doenças de plantas fruteiras. Viçosa MG. UFV. v. 1. pp. 1-45.

Angel ND, Ramos MA, Ortiz DT, São Jose AR (2006) Enfermidades del mango. In: Oliveira SMA, Terao D, Dantas SAF, Tavares SCCH (Eds.) Patologia pós-colheita: frutas, olerícolas e ornamentais tropicais, Brasília. Embrapa Informação Tecnológica. pp. 733-774

Assis JS (2004) Embrapa Semi Árido. Disponível em: <http:// sistemasdeproducao.cnptia. embrapa.br/ FontesHTML/Manga/ CultivodaMangueira/colheita.htm $>$ Acesso em Janeiro 25, 2008

Chillet M, Hubert O, Rives MJ, Lapeyre de Bellatre L (2006) Effects of the physiological age of bananas on their susceptibility to wound anthracnose due Colletotrichum musae. Plant Disease 90:1181-1185.

Chitarra MIF, Chitarra AB (2005) Pós-colheita de frutos e hortaliças: fisiologia e manuseio. Lavras MG. UFLA.

FAO (2007) Food Agricultural Organization. Statistical - database. Disponível em: www.apps.fao.org. Acesso em: Novembro 03, 2007. 
Freire FCO, Viana FMP, Cardoso JE, Santos AA (2004) Novos hospedeiros do fungo Lasiodiplodia theobromae no estado do Ceará. Fortaleza. Embrapa Agroindústria Tropical. (Comunicado Técnico, 91).

Hartill WFT (1991) Postharvest diseases of avocado fruit in New Zealand. Crop Hort Science 19:297-304.

Johnson GI (1992) Biology and control of stem-end rot pathogens of mango. Queensland, Austrália. University of Queensland.

Lima JAS (1996) Caracterização patogênica, fisiológica, cultural e isoesterásica de isolados de Botryodiplodia theobromae (Pat.) agente causal da morte descendente da mangueira (Mangifera indica L.). Dissertação de Mestrado. Recife PE. Universidade Federal Rural de Pernambuco.

Menezes M, Assis SMP (2004) Guia prático para fungos fitopatogênicos. $2^{\mathrm{a}}$ ed. Recife PE. Imprensa Universitária da UFRPE.

Moraes WS, Castro HA, Leite E, Naves RL, Campos SS, Amorim L, Kimura M (1995) Caracterização morfológica e cultural de Botryodiplodia theobromae em diferentes meios de cultura. Fitopatologia Brasileira 20:366. (Resumo)

Okazaki L (2007) Alta produtividade favorece Brasil no mercado internacional de manga, Hortifruti Brasil 1:7-13.

Oliveira SMA, Terao D, Dantas SAF, Tavares SCCH (2006) Patologia pós-colheita: frutas, olerícolas e ornamentais tropicais, Brasília DF. Embrapa Informação Tecnológica.

Pennycook SR, Samuels GJ (1985) Botryosphaeria and Fusicoccum species associated with ripe fruit rot of Actinidia deliciosa (kiwifruit) in New Zealand. Mycotaxon. 24:445-458.

Pereira AL, Silva GS, Ribeiro VQ (2006) Caracterização fisiológica, cultural e patogênica de diferentes isolados de Lasiodiplodia theobromae. Fitopatologia Brasileira 31:572-578.

Pessoa WRLS, Oliveira SMA, Dantas SAF, Tavares SCCH, Santos AMG (2007) Efeito da temperatura e período de molhamento sobre o desenvolvimento de lesões de Colletotrichum musae em banana. Summa Phytopathologica 33:147-151.

Ram C (1993) Características culturais, esporulação e violência do "strain" do Botryodiplodia theobromae, agente causal da queimadas-folhas do coqueiro (Cocos nucifera). Fitopatologia Brasileira 18:143-146

Ramos LJ, Lara SP, Mcmillan Jr RT, Narayanan KR (1991) Tip dieback of mango (Mangifera indica) caused by Botryosphaeria ribis. Plant Disease 75:315-318.

Silva AC (1996) Botânica da mangueira. In: São Jose AR, Souza IVB, Duarte Filho JM, Morais OT (Eds.). Manga - Tecnologia de produção e mercado. Bahia. Universidade Estadual do Sudoeste da Bahia. pp. 7-15.

Slippers B, Johnson GI, Crous PW, Denman S, Coutinho TA, Wingfield BD, Wingfield MJ (2005) Phylogenetic and morphological re-evaluation of the Botryosphaeria species causing diseases of Mangifera indica. Mycologia 97:99-110.

Slippers B, Crous PW, Denman S, Coutinho TA, Wingfield BD, Wingfield MJ (2004) Combined multiple gene genealogies and phenotypic characters differentiate several species previously identified as Botryosphaeria dothidea. Mycologia 96:83-101.

Tavares SCCH (2002) Epidemiologia e manejo integrado de Botryodiplodia theobromae - situação atual no Brasil e no mundo. Fitopatologia Brasileira 27:46-52.

Tavares SCCH (1995) Principais doenças da mangueira e alternativas de controle. Informações técnicas sobre a cultura da manga no Semi-Árido Brasileiro. Brasília. Embrapa Informação Tecnológica.

Tavares SCCH, Menezes M, Choudury MM (1991) Infecção de mangueira por Botryodiplodia theobromae, Lat. na região semiárida de Pernambuco. Revista Brasileira de Fruticultura 13:163166.

Zonta EP, Machado AA (1996) Sistema de análise estatística para microcomputadores. Pelotas RS. UFPEL.

Recebido 5 Maio 2008 - Aceito 28 Dezembro 2008 - TPP 8052

Editor Associado: Lilian Amorim 